\title{
A REVIEW ON NON-CIRCULAR JOURNAL BEARINGS
}

\section{JIJO JOSE \& NIRANJANA BEHERA}

School of Mechanical Engineering, VIT University, Vellore, Tamilnadu, India

ABSTRACT
Hydrodynamic bearings depend on the high journal speed to move the pressurized fluid in a wedge between the
faces. Instabilities due to oil whip and whirl are usually observed when using hydrodynamic circular journal bearing in
high speed rotating machinery. To overcome these difficulties, non-circular bearings are usually preferred over circular
bearings. A non-circular journal bearing has increased shaft stability, increased oil flow and reduced power losses as
compared to circular journal bearing under proper working conditions. This paper deals with a review of major works
conducted on non-circular bearings to improve the performance characteristics. The effect of incorporating pressure
dams in bearings, use of porous bearing, use of non-Newtonian lubricants and micropolar lubricants on the static and
dynamic characteristics of the bearing have also been analyzed.
KEYWORDS: Multi-Lobed Bearing, Static Characteristics, Dynamic Characteristics, Hydrodynamic Lubrication \&
Reynolds Equation

Received: Nov 22, 2017; Accepted: Dec 13, 2017; Published: Jan 05, 2018; Paper Id.: IJMPERDFEB201825

\section{INTRODUCTION}

In hydrodynamic lubrication the load supporting the fluid film is developed by the relative motion and shape of the sliding surface. A journal bearing is a sliding contact bearing working on hydrodynamic lubrication and which supports the load in radial direction. Using hydrodynamic circular journal bearing in high-speed rotating machinery may cause instabilities due to whirl and oil whip. In situations like this, non-circular bearings are selected over circular bearings because of their better dynamic behavior. It has been found that as the circular journal bearing have only a single active oil film during its working, the rise in temperature is quite high in these bearing. Therefore a development in the field of non-circular bearing occurred, which have more than one active oil film during its operation. Hence non-circular bearings will be having greater stiffness, better damping characteristics and reduced temperature in the oil film when compared to the circular journal bearings. Among non-circular journal bearings, lemon bore, elliptical offset-halves, three-lobed and four-lobed configurations are the frequently used ones. Multi-lobe bearings are mostly employed in light loaded and highspeed applications due to their remarkable stability than any other bearing designs. Non-circular bearings may have positive or negative impact on the static and dynamic performance of a rotor-bearing system.

From an analysis of power losses and steady-state load capacity on multi-lobe bearing it has found that, in high-speed applications, more importance should be given to rotor stability than the bearing load-carrying capacity. Pinkus (1956 a, b, c) studied experimentally that tilting pad bearing configuration has better stability than a threelobe, elliptic and grooved-bearing.

Lund (1968a) investigated the stability of multi-lobe bearing based on linearizing the Reynolds equation by perturbation theory to study the effect of preload on stability. The first time transient technique was 
demonstrated in the analysis of full gas journal bearing and has been extended into more complex models such as a tilting pad rotor system with 18 degrees of freedom. The hydrodynamic bearing forces were solved by Reynolds equation using a numerical solution. This procedure was very accurate, extremely time-consuming and uneconomical to use as a basic design tool.

Few researchers worked for improving the bearing performance by using micropolar, non-Newtonian lubricant, etc. A two-lobed pressure dam bearing using micropolar lubricant exhibits high load carrying capacity (Sharma \& Rattan (2010). The static load of an offset bearing improves by using non-Newtonian lubricant (Chetti,(2010) and Crosby \& Chetti (2009). It has been studied that the performance of a three-lobe (Mehta \& Rattan (1993) and inverted three-lobe (Batra et al. (2011) pressure-dam bearing is far better than an ordinary multi-lobe bearing.

In a porous bearing as the journal speed increases, the lubricant present in the tiny cavities of the bearing gets expelled out and provides a hydrodynamic film. The static and dynamic performance characteristics of two-lobed and three-lobed hydrodynamic porous bearing improve as compared to an ordinary multi-lobe bearing (Sinhasan et al.(1980), Malik et al. (1981a)).

Non-circular bearings may have positive or negative impact on the static or dynamic performance. Also by using different types of lubricants such as micropolar, non-Newtonian, etc. Hence a review on non-circular journal bearing is necessary. In this article a review has been conducted on the researches performed on various types of non-circular journal bearings.

\section{REVIEW OF NON-CIRCULAR BEARINGS}

The following sections briefly explain the various researches conducted on non-circular bearings and their influences on the bearing performance. The different sections includes two-lobed, three-lobed and four-lobed bearings, micropolar lubrication, lubrication with non-Newtonian lubricants, porous bearings and comparative study of different bearing configurations.

\section{Two-Lobed Bearing}

Kumar et al. (1980) computed a design data using a variational solution which included Sommerfeld number, equilibrium locus, damping coefficient, fluid film stiffness, temperature rise parameter and end flow friction parameter. In this work, the flow field was calculated based on the hydrodynamic lubrication theory. From the analysis it was found that the attitude angle decreases sharply beyond a certain value of eccentricity ratio. Therefore a sudden increase in eccentricity ratio could be observed for the lower lobe and comparable decrease in eccentricity for the upper lobe. Due to this the vertical load support increased. The end flow varied with Sommerfeld number similar to that reported in (Pinkus et al. (1961). With the increase in Sommerfeld number, the friction coefficient increases and the temperature rise parameter decreases.

For offset halves journal bearing, Malik et al., (1982) developed a design data with offset factor 0.5 and having different aspect ratios in the laminar and turbulent regimes. Using Galerkin's method, a variational solution of Reynolds equation was used in the development of data using analytical procedure. A comparison of this analysis was done and was found to be in good agreement (Lund \& Thomsen (1978)). 
Some two-lobe bearing configurations were compared with elliptical and offset halves bearing and their geometrical variation as shown in figure 1 (Malik (1983). From the analysis it was concluded that configuration 1 had the maximum load carrying capacity for the largest operating eccentricity among all the four bearing configurations. When the eccentricity increased the difference in load carrying capacity was found to decrease. Oil requirement and the heat dissipation capacities for the bearing will be in the increasing order from configurations 1 to 4 . Configuration 3 generally had the best stiffness and damping characteristics among all the four configurations. Dynamic characteristics were good for configurations 1 and 4, but only in the limited range of operation.

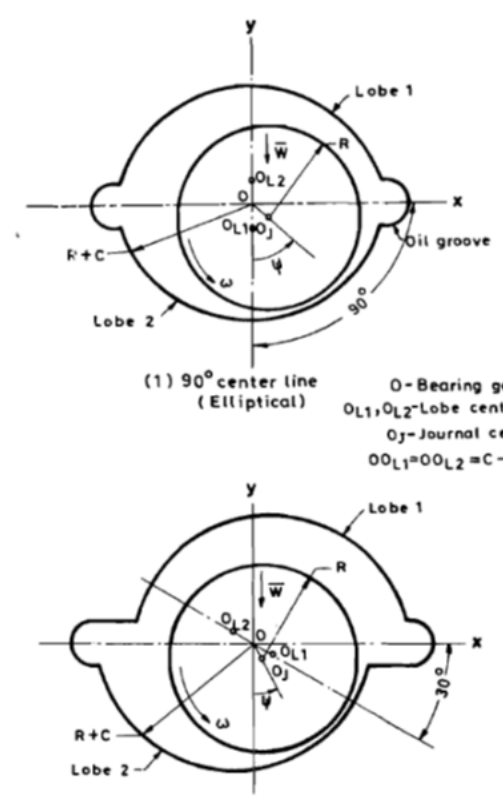

(3) $30^{\circ}$ center line

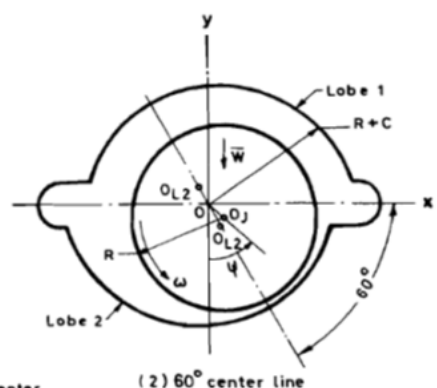

(2) $60^{\circ}$ center line

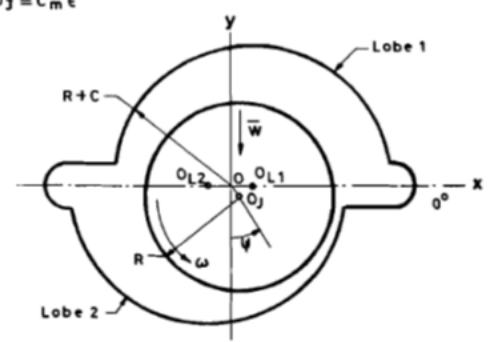

(4) $0^{\circ}$ center line (Oftset halves)

Figure 1: Two-Lobed Configurations [18]

Soni et al. (1985) studied the effect of turbulence by solving the modified Reynolds equation using the linearized turbulence theory proposed. The results based on linearized theory and non-linearized theory was compared by $\mathrm{Ng} \& \mathrm{Pan}$ (1965). It shows that linearized theory gives accurate results only at a value of Reynolds number 3000.

Dwivedi et al. (2013) investigated the effect of geometry of lobes and L/D ratio (0.75, 1.0 and 1.5) on the static characteristics of two-lobed journal bearing. The effect of static characteristics of the two-lobe elliptical and offset profile bearings were studied in this work. The Reynolds equations in the steady state form in two dimensions were solved by finite difference method (FDM). From the investigation it was observed that the load capacity of elliptical bearing was better as compared with two lobe offset bearing.

\section{Three-Lobed Bearing}

Falkenhagen et al. (1972) studied the general transient motion and stability characteristics of a finite-width threelobe bearing with an incompressible fluid having cavitation effect. The hydrodynamic forces on the bearing were evaluated by both approximate method and a finite-difference method. The approximate method was accurate and 100 times faster than FDM. The stability curves for rigid vertical rotor developed were compared with experimental data of NASA as well as analytic work conducted by (Lund (1968a)). 


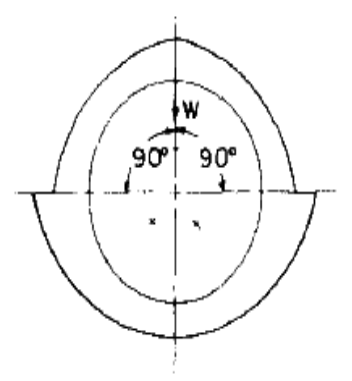

(a)

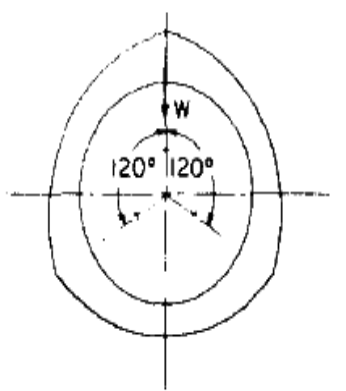

(b)

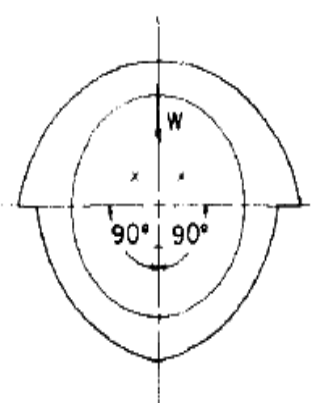

(c)

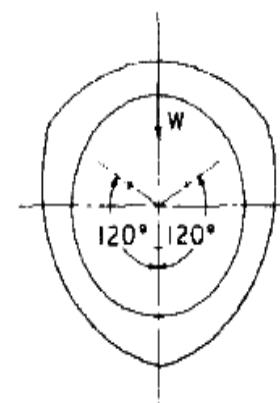

(d)

Figure 2: The Three-Lobed Bearing Configurations: (a) Unsymmetric Upright (b) Symmetric Upright (c) Unsymmetric Inverted (d) Symmetric Inverted [23]

A comparative study based on the dynamic and static performance of some three-lobed bearing configurations (figure 2) was done by Sinhasan et al. (1980). The same procedure was employed in the analysis of two-lobed, three-lobed and offset bearing by Sinhasan et al. (1981), Malik et al. (1981b), Kumar et al. (1980), Malik et al. (1982) and Malik et al. (1981a) were used in this analysis also. The result was found to be matching with those of Lund \& Thomsen (1978), Pinkus (1959) and Lund (1965). From the analysis it was seen that the static load support was the best for the symmetric upright configuration. For both un-symmetric and symmetric inverted configurations the dynamic performance appeared more promising.

Malik et al. (1981b) developed a design data of three-lobed bearing working in the laminar and turbulent regimes of operation. The same solution procedure which they employed in his two-lobe bearing work (Malik et al. (1982)) was used here. It was found that the bearing load support and power loss increase with Reynolds number and eccentricity. An increase in critical mass of the journal and stiffness and damping coefficients with increase in Reynolds number indicated an increased dynamic performance of the bearing. It was seen that in the turbulent regime, the overall dynamic performance of the bearing was improved.

Malik et al. (1981c) investigated the effect of tilting by varying the tilt angle and keeping all the bearing parameters fixed. The tilt angle was varied from 0 to $60^{\circ}$ maintaining $15^{\circ}$ intervals. From the analysis, it was found that maximum value of the dynamic coefficient curve was in between $30^{\circ}-60^{\circ}$ tilt angle range. The optimum tilt angle considering stability margin was found to be nearly $45^{\circ}$. Bearing operation at tilt angles of $30^{\circ}$ and $45^{\circ}$ configurations have the same maximum load capacity. A $30^{\circ}$ tilt bearing provided the highest load capacity when working at high eccentricities. Oil consumption, rose as tilt angle increased and therefore the heat dissipation properties also got improved. The tilted configurations of $15^{\circ}$ to $45^{\circ}$ tilt angles had the best elastic and damping characteristics than with a symmetric three-lobe bearing.

Flack \& Lanes (1982) investigated the stability of a rigid rotor mounted on a three-lobed bearing with systematically varying the load orientation, preload factor and offset factor. It was found that bearings having normal preload factors and offset factors of 0.1 or lesser value were more balanced than those with high offset factors. For a given load orientation and preload value, a specific offset factor exists which was having minimum stability (similar bearings geometries should be avoided). Finally, the stability of the rotor increased as the preload factor increases.

Nair et al. (1987) studied the consequence of the bearing liner deformity on the working of a three-lobe journal 
bearing system. An iteration scheme and the FEM were used to solve continuity equations and the 3D Navier-Stokes equation in cylindrical coordinate for the lubricant flow field and for finding the dislocation of the bearing liner the 3D elasticity equations were used. To calculate the flexibility of the bearing liner a dimensionless deformation coefficient as a function of modulus of elasticity of the liner material, viscosity of the lubricant, journal speed, geometry of the bearing and the thickness of the bearing liner, was defined. From the analysis it was found that with increase in deformation coefficient the peak pressure reduced. At low deformation coefficients the positive pressure zone increased. The value of attitude angle, load-carrying capacity, power loss and end leakage decreased with increase in deformation coefficients. As the deformation coefficient increased, minimum film thickness increased. At low values of eccentricity ratios with increase in deformation coefficients the damped frequency of whirl decreased.

Chandrawat \& Sinhasen (1990) investigated the non-circular bearings considering EHD effects. This analysis was actually a continuation of their previous investigation of Chandrawat \& Sinhasen (1988) on a two-lobe bearing. The data developed were for piezoviscous and isoviscous lubricants, and the transition effect was considered in the super laminar flow regime in calculating the bearing characteristics. The 3D elasticity equation for the bush and Reynolds equation were solved using an iteration scheme and FEM by Chandrawat \& Sinhasen (1988). A linear complementarity problem approach was used by Chandrawat \& Sinhasen (1987) to provide the EHD pressure field and the Reynolds boundary, while the equilibrium locus of the journal centre was obtained by a suitable iterative procedure (Chandrawat \& Sinhasen (1988)). It was found that the minimum film thickness was greatly reduced and side flow increased due to bearing flexibility.

The performance evaluation of a three-lobed bearing having pressure dams was first done by Mehta \& Rattan, (1993). At the lobes 1 and 3, a rectangular dam was cut circumferentially and a circumferential relief-track was cut midway in the second lobe of the bearing. Only half of the lobe was considered for analysis for lobes 1 and 3 having pressure dams and for lobe 2 having a relief-track respectively, since the pressure profiles at these lobes were identical about the centre of the bearing. By Gauss-elimination method the resulting matrix was solved. It was observed that pressures developed in lobes 1 and 3 of a three-lobe pressure-dam bearing were high in comparison with a normal three-lobed bearing. Oil-flow coefficient and minimum film thickness decrease whereas friction coefficient as well as the ellipticity ratio increases for a specific value of Sommerfeld number. The value of minimum threshold speed increases from 4.1 to 14.95.

An investigation was conducted on the working of an inverted three-lobe pressure dam bearing supporting rigid as well as flexible rotors by Batra et al (2011). In an inverted three-lobe bearing by making pressure dams on the upper-lobe and two relief-tracks on the lower two lobes, the bearing was prepared. The L/D ratio was varied from 0.8-1.5. Using FEM, the Reynolds equation was analyzed for a pressure profile. From the results it was proved that for an inverted three-lobe pressure dam bearing the stability increases as L/D ratios decrease for both the rotors.

Chasalevris (2015) developed a design data for a finite length three-lobe bearing working in the laminar regimes. Cavitation effect was considered at the fluid film pressure distribution. The results for various bearing characteristics were obtained for a range of Sommerfeld number and for different types of load orientation. From the analysis it was inferred that in order to improve the evaluation time the solution with Bessel function should be used in rotor dynamic algorithms. The static characteristics of the three-lobe bearing could be found out much faster using this design data with high accuracy than by any other numerical method. 


\section{Four-Lobed Bearing}

Malik (1983) conducted a comparative study on the performance of the tilted and symmetric four-lobed journal bearing configurations. The weighted residual principle along with Galerkin's criterion was employed to develop the finite element equations. From the analysis, it was found that performance of the parent symmetric bearing configuration was improved by tilting. A tilted bearing have improved heat dissipation, increased minimum film thickness, and lesser power loss for the same load support when compared to a symmetric bearing. The dynamic characteristics of a properly tilted bearing were found exceptional to that of the symmetric bearing.

The stability of submerged four-lobe oil bearing undergoing dynamic loading condition was investigated by Pai \& Majumdar (1992). They predicted the journal centre trajectories for a submerged bearing undergoing the following load conditions 1) unidirectional constant load 2) unidirectional periodic load and 3) variable rotating load using a nonlinear transient method. Under similar load conditions, the trajectories of the submerged plane cylindrical bearing were compared with those for journal centre obtained. Using Jakobsson-Floberg-Olsson (JFO) cavitation model, the Reynolds equation was integrated. The analysis incorporates the prehistory of the oil film. The cavitation model along with oil film history gives sufficient information about the dynamic condition of submerged bearings. It was found from the analysis that fourlobe bearings were found stable but the plain bearings were found unstable at low values of eccentricity ratios.

Significance of pressure dams in the dynamic performance of a four-lobe pressure-dam bearing was investigated by Bhusan et al (2002). It was made by consolidating two relief tracks in the lower lobes and two pressure dams in the upper lobes of a regular four-lobed bearing. The solution procedure employed in Mehta \& Rattan (1993) was used here also. It was observed that with the incorporation of pressure dams and relief tracks the stability of a four-lobe bearing increases. As the relief-track axial width increases, the stability of the four-lobe pressure-dam bearing was found to increase. The stability was found to increase as the L/D ratio decreases.

\section{Porous Bearing}

After the initial work by Morgan \& Cameron (1957) regarding the lubrication of porous bearings, the performance of two-lobed porous and non-porous hydrodynamic journal bearings was compared by Sinhasen et al. (1980). From the investigation it was found that at lower eccentricity, the effect of porosity was negligible. A two-lobed porous bearing works with higher attitude angle and higher eccentricity than with an ordinary two-lobed bearing, for the same load support. As the porosity increase, the dynamic coefficient and critical mass decreases but the side leakage and frictional power loss increases. Porosity reduced the stability of the journal bearing system.

The nature of transient motion and stability margin were investigated for three-lobe porous bearing (Malik et al. (1981a)). Routh's criterion was used to calculate it based on the critical mass of journal. For the same eccentricity as the load permeability parameter increased, it was found that the load support of the bearing reduced. For the same load support, the attitude angle and operating eccentricity increased as the permeability parameter increased. The stiffness and damping coefficients and power loss gradually decreased as the porosity increased. It was found that the static and dynamic characteristics vary in a similar manner for two-lobed and three-lobed journal bearing.

\section{Micro-polar Lubrication}

The performance of two-lobe pressure dam bearing was analyzed with micro-polar lubrication (Sharma \& Rattan (2010). A rectangular step was circumferentially cut in the upper lobe and a relief track was provided for the bottom lobe. 
The modified Reynolds equation under micro polar lubrication was used here. From the analysis it was found that the load carrying capacity of the bearing rose with micropolar lubrication. The attitude angle decrease with micropolar lubrication.

Coupling number and characteristics length distinguish a micro polar fluid from a normal Newtonian fluid. The coupling number is a dimensionless term which couples the angular momentum and linear momentum occurring due to the rotational effect of immersed micro particles present in fluids. Coupling effect will be high at higher values of coupling number. As the coupling number approaches to zero, the fluid behaves as Newtonian. The characteristics length indicates the interaction of micro polar fluid with the film gap. When the characteristics length term vanishes in the Reynolds equation the equation reduces for Newtonian fluid. At higher values of characteristics length the fluid behaves as Newtonian.

The effect of micro polar lubricant on the static characteristics of multi-lobed bearings (two, three and four-lobed bearings) were studied by Rahmatabadi et al. (2010a). From the analysis it was concluded that using micro polar lubricant in circular bearing, improved the load carrying capacity, decreases coefficient of friction and side leakage. The attitude angle decreased with micro polar lubrication.

Rahmatabadi et al. (2010b) carried out the comparative performance evaluation of a three-lobe journal bearing and circular bearing having finite length lubricated with micropolar fluids and by Newtonian lubricant using generalized differential quadrature method (GDQ) method. With GDQ method the solution for lubrication problems could be obtained easily with high accuracy and taking lesser computation time. At higher eccentricities, the factors characteristics length and coupling number improved the bearing characteristics. Preload factor, side leakage and volume flow rates remains unaffected by the micropolarity of the lubricant.

Chetti (2014) studied the effect of micropolar fluids in a three-lobed bearing by determining its dynamic characteristics. FDM was applied to obtain the solution for Reynolds equation. For various characteristics length and coupling number the dynamic characteristics were determined. The critical mass of the bearing increased and the whirl ratio decreased as the coupling number increased. The bearing stiffness and damping coefficients with a micropolar fluid were greater than those of Newtonian fluid. The stability was found to be improved by using a micropolar fluid.

Mehrjardi et al. (2016a) studied the stability characteristics of non-circular two, three, and four-lobe journal bearings with micropolar lubricant. The performances of these non-circular bearings were evaluated based on critical mass parameter, load carrying capacity, and whirl frequency ratio. From the investigation it was found that increasing the eccentricity ratio, the micropolarity feature of lubricant increases the static and stability performance of the bearing. For lobed bearings, the whirl frequency ratio for the linear analysis decreases with either decreasing the preload factor or by increase of the micropolarity characteristic of lubricant and the eccentricity ratio of bearing. For non-circular bearings, any decrease of the preload factor or any increase of the micropolarity characteristic of the lubricant as well as eccentricity ratio cause an increase in the critical mass term.

Sharma \& Krishna (2015) investigated the significance of L/D Ratio on the working of two-lobe pressure dam bearing lubricated with micropolar lubricant. The dynamic characteristics of the bearing were evaluated at various $\mathrm{L} / \mathrm{D}$ ratios. With increase in the aspect ratios, the load capacity increases. For lower value of attitude angle, the characteristic length will be lower. As characteristic length increases, the attitude angle increases. At higher dam width ratio, the damped frequency of whirl was found to be lower while threshold speed and critical mass increase. 
Rahmatabadi et al., (2011)studied the effect of preload factor on two, three and four-lobed bearing lubricated with micropolar lubricant on the static performance characteristics. From the analysis, it was observed that the maximum pressure occurred for the four-lobe bearing. The side leakage flow, load carrying capacity, and attitude angle increased when the preload value increased. Bearings with larger number of lobes had higher load carrying capacity at smaller preload values. The results proved that by reducing the coefficient of friction, the micropolarity of the lubricant improves the performance of lobed bearing.

Mehrjardi et al., (2016b) studied the importance of preload factor on the non-linear and linear and dynamic behavior of two-lobed and three-lobed journal bearings by using GDQ and Runge-Kutta methods. To solve the governing Reynolds equation and time-dependent dynamic equations of rotor motion respectively, the GDQ method and fourth-order Runge-Kutta techniques have been used. By decreasing the preload factor, the dynamic stability of the noncircular bearings was enhanced. The results of linear model were more conservative in different cases. Nonlinear analysis reveals that the dynamic responses of the lobed bearings appear in different manners by changing the preload factor.

\section{Non-Newtonian Lubricant}

Using a non-Newtonian lubricant in a two-lobed bearing the transient response of the bearing was investigated by Sinhasan \& Goyal (1995). The continuity equation and 3D momentum equations were solved for a Newtonian lubricant using FEM and the solution was solved using iteration. In iteration, the viscosity term in the cubic shear stress law was varied to include the non-Newtonian effect. By integrating the equations of motion by Runge-kutta method, the non-linear and linear journal centre trajectories were obtained. Thus linearized equations of motion were used to find the limit cycles when the mass of the journal and critical mass becomes equal for both Non-Newtonian and Newtonian lubricant at various loads. Linearized equation of motion predicts a higher value of stability than by non-linearized equation of motion.

Effect of coupled stress field in a two-lobe bearing was studied by Crosby and Chetti (2009). A comparative study of a two-lobed bearing lubricated with non-Newtonian lubricant and Newtonian lubricant was done to determine the importance of couple stress parameter. In this work, the Reynolds equation for coupled stress field used by Guha (2004) was applied. From the analysis, it was observed that larger load carrying capacity and lubricant pressure was observed for bearings lubricated with non-Newtonian lubricant. As the couple stress parameter increased, the stiffness and damping coefficient, stability increased. As the couple stress parameter reduced, the side leakage, frictional coefficient and attitude angle increased. It was also observed that by using a non-Newtonian lubricant, the bearing was found to be more lubricated than with a Newtonian lubricant.

Chetti (2010) studied the effect of couple stress field was studied in an offset bearing lubricated having nonNewtonian lubricant. For a rigid and deformable bearing, the characteristics of the bearing were determined for different values of couple stress parameter. The solution procedure was the same as detailed in work of Crosby \& Chetti (2009). From the analysis, it was observed that the pressure and load carrying capacity was found more for the bearing lubricated with couple stress fluid than with Newtonian fluid. The attitude angle, load bearing capacity, and side leakage will be more for rigid bearing than a deformable bearing. When the couple stress parameter increased, the coefficient of friction, attitude angle and side leakage decreased.

\section{COMPARATIVE ANALYSIS OF NON-CIRCULAR BEARINGS}

This section includes the various analyses done on different multi-lobe bearings and its comparisons. 
The performance of four bearings with various designs (circular-cylindrical, four-lobed, two-lobed and tilting pad bearings) was compared for ideal conditions by Glienicke et al. (1980). Major deviations from ideal conditions were observed for high circumferential speed and high specific bearing loads. The static load capacity was reduced by a static misalignment in the bearing, but it does not have much impact on the vibration and stability behavior.

The linear stability and nonlinear behavior of single mass rotor in four different multi-lobe configurations (elliptical "lemon" shaped bearing, offset elliptical bearing, three-lobed bearing and four-lobed bearing) were studied (Li et al. (1980)). A time transient procedure based on a variational principle was presented using the series solution of the Reynolds equation. A non-linear transient analysis of a rigid rotor in each of these bearings was done above and below the threshold speed. To obtain the frequency content of the nonlinear orbit, a numerical fast Fourier transform analysis was employed. It was found that using the variational approach, an accurate and economical procedure was developed suitable for the time transient analysis of bearing for any L/D ratio. The elliptical bearing has excellent stability. For operation in a region of light load or close clearance, the offset bearing was found to be superior. Elliptical bearing has the most violent whirl vibration amplitude and offset bearing exhibits the least amount of sub synchronous vibration when it was operated above the linear stability threshold value. Transient simulations showed that the four-lobe bearing has higher bearing forces than a three lobe bearing after it has become unstable. The offset bearing has superior dynamic quality above, and below the stability threshold in lightly loaded and close clearance applications.

Wahed et al. (1982) studied different bearing types (plain circular, elliptical, three-axial groove, three-lobe, and the three-pocket type) frequently used journal bearings for stability and unbalance response for linear and nonlinear analysis. Using the linearized dynamic coefficient, the stability analysis was carried out. The unbalanced response was determined by non-linear analysis. The effect of bore shape, including grooves and pockets, on the minimum film thickness and on the forces transmitted was investigated. A numerical finite difference solution with Reynolds boundary conditions in both nonlinear and linear analysis was done using the effective viscosity concept. It was observed that all parameters which stabilize the bearing increase the bearing sensitivity to large unbalances. In the order of increasing resistance to unbalance loading, the bearings were ranked as follows: three pockets, three-axial groove, offset three-lobes, elliptic, circular.

Chandra et al. (1983) compared the dynamic behaviour and steady state behaviour of certain gas-lubricated bearing configurations (Offset halves bearing, three-lobed bearing, lemon bore bearing, and four-lobed bearing). The dynamic analysis used was established on work of Lund (1967) and Lund (1968b). The comparison was based on the load capacity and compressibility number. It was found that the offset-halves bearing has superior dynamic characteristics. In the increasing order of dynamic stability, the configurations may be placed as: lemon-bore; four-lobed, three-lobed bearings.

FEM was used for comparing the dynamic coefficients in of multi-lobed bearings (two-axial groove, two, three and four-lobed journal bearings) (Dargaiah et al. (1993)). The matrix method followed by Shang \& Dien (1989) was used here. The lobe eccentricity ratios and attitude angle were obtained for each bearing for a given eccentricity ratio and attitude angle. From the analysis it was found that the proposed FEM was accurate and has no convergence problems.

A method for prediction of dynamic coefficients and nonlinear simulation of multi-lobed bearings (offset bearing, three-lobe, elliptical and two-axial groove) was developed by Rao et al. (2001) To evaluate the transient response and stiffness and damping coefficients, a semi-analytical method of Sommerfeld bearing solutions and unsteady Ocvirk were 
employed. When eccentricity ratios become higher, the dynamic coefficients calculated by this method matches well with the results of infinitesimal perturbation method. For two-axial groove bearing the nonlinear dynamic response was obtained by a synchronous excitation force.

A numerical method for the determination of dynamic coefficients considering cavitation effect in four different multi-lobed bearings (elliptical, two axial groove, three lobe and offset cylindrical bearings) was suggested by Rao \& Sawicki (2001). According to the requirement of JFO conditions (Elrod (1981)) a universal mass conservation algorithm was proposed for predicting the cavitation regions. The JFO theory states that fluid get shifted in the form of striations extending the journal and bearing surfaces in the cavitation field. As the film rupture boundary was anticipated based on the continuity fluid flow in journal bearings, the results of the bearing dynamic coefficients found using cavitation algorithm matches well with the published work based on Reynolds boundary condition.

\section{CONCLUSIONS}

In this paper, various researches conducted on non-circular bearings have been studied. The following conclusions have been drawn from the study:

- In a three-lobed bearing, the static and dynamic characteristics depend on the type of bearing configuration. Symmetric upright configuration shows better static load support, whereas un-symmetric and symmetric inverted configurations show better dynamic performance.

- Stability of the two, three and four-lobed bearings increases to a large extent by incorporating pressure dams.

- The static and dynamic characteristics vary in a similar manner for two-lobed and three-lobed porous bearing. In lobed bearings, the stability decrease as the porosity increases.

- Lobed bearing with non-Newtonian fluid as lubricant induce larger load carrying capacity and larger lubricant pressure than a Newtonian lubricant.

- Lobed bearings with micropolar lubricant show higher stiffness and damping coefficients than a Newtonian fluid lubricant. Hence stability gets improved by using micropolar lubricant.

- Elliptical bearing has a higher load carrying capacity than a two-lobed bearing of any configuration. Elliptical and offset halves configurations have good dynamic characteristics than any other two lobed configurations.

- Stability of the lobed bearing can be improved by changing the location of lobe or tilting within a specified range.

- Using micropolar lubrication in pressure dam bearings increases the load carrying capacity of the bearing. Stability of the lobed bearing also increases by incorporating pressure dam with micropolar lubrication.

- Offset-halve bearing have superior dynamic characteristics. The offset-halved bearing operates with the lowest power loss and stable dynamic performance when compared with lemon bore, three lobe and four lobe configurations. The load carrying capacity of an offset bearing lubricated with non-Newtonian fluid is more than a bearing lubricated with a Newtonian fluid.

\section{REFERENCES}

1. Pinkus, O. (1956a). Analysis of elliptical bearings. Transactions of ASME, 78, 965-973. 
2. Pinkus, O. (1956b).Power losses in elliptical and 3-lobe bearings. Transactions of ASME, 78,899-904.

3. Pinkus, O. (1956c).Experimental investigation of resonant whip. Transactions of ASME, 78, 975-983.

4. Lund, J.W. (1968a). Rotor-bearing dynamics design technology, part VII: The Three-Lobe bearing and floating ring bearing. Technical Report AFAPL-TR-65-45, Wright-Patterson Air Force Base, Ohio.

5. Sharma, S., \& Rattan, S.S. (2010). Micropolar lubricant effects on the performance of a two-lobe bearing with pressure dam. International Journal of Engineering Science and Technology, 2, 5637-5646.

6. Chetti, B. (2010). Elastohydrodynamic analysis of an offset journal bearing lubricated with couple stress fluid. International Journal of Engineering Research in Africa, 2, 53-62.

7. Crosby, W.A., \& Chetti, B. (2009). The static and dynamic characteristics of a two-lobe journal bearing lubricated with couple-stress fluid. Tribology Transactions, 52, 262-268.

8. Mehta, N.P., \& Rattan, S.S. (1993). Performance of three-lobe pressure-dam bearings. Tribology International, 26, 435-442

9. Batra, N.K..,et al. (2011). Effect of L/D Ratio on the performance of an inverted three-lobe pressure dam bearing. Journal of Engineering and Technology, 1, 94-99.

10. Sinhasan, R.,et al. (1980). Analysis of two-lobe porous hydrodynamic journal bearings. Wear, 64, 339-353.

11. Malik, M.,et al. (1981a). On performance characteristics of three-lobe porous hydrodynamic journal bearings. ASLE Transactions, 24, 37-41.

12. Kumar, A.,et al.(1980). Performance characteristics of two-lobe hydrodynamic journal bearings. ASME, 102, 425-429.

13. Pinkus, O., Sternleicht, B. (1961). Theory of hydrodynamic lubrication: McGraw-Hill.

14. Malik, M.,et al. (1982). Design data for offset-halves journal bearings in laminar and turbulent regimes. ASLE Transactions, $25,133-140$.

15. Lund, J.W., Thomsen, K.K. (1978). A calculation method and data for the dynamic coefficients of oil-lubricated journal bearings. Dyrobes, 1-29.

16. Malik, M. (1983). A comparative study of some two-lobed journal bearing configurations. ASLE Transactions, 26,118-124.

17. Soni, S.C.,et al. (1985). Non-linear analysis of two-lobe bearings in turbulent flow regimes. Wear, 103, 11-27.

18. Ng, C.W., \& Pan, C.H.T. (1965). A linearized turbulent lubrication theory. Journal of Basic Engineering, 87, 675-688.

19. Dwivedi, V.K.,et al. (2013). Effect of geometry of lobes and L/D ratio on the static performance of 2-lobe hybrid journal bearing. International Journal of Pure and Applied Research in Engineering and Technology, 1, 64-71.

20. Falkenhagen, G.L.,et al.(1972). Stability and transient motion of a vertical three-lobe bearing system. Journal of Engineering for Industry, 5, 665-676.

21. Sinhasan, R.,et al.(1981). A comparative configurations study of some three-lobe bearing. Wear, 72, 277-286.

22. Malik, M.,et al.(1981b). Design data for three-lobe bearings. ASLE Transactions, 24,345-353.

23. Pinkus, O. (1959). Analysis and characteristics of three-lobe bearings. Journal of Basic Engineering, 8, 49-55.

24. Lund, J.W. (1965). Rotor-bearing dynamics design technology, part III: The Three-Lobe bearing and floating ring bearing. Technical Report AFAPL-TR-65-45, Wright-Patterson Air Force Base, Ohio. 
25. Malik, M.,et al.(1981c). Performance characteristics of tilted three-lobe journal bearing configurations. Tribology International, 345-349.

26. Flack, R.D., \& Lanes,R.F. (1982). Effects of three-lobe bearing geometries on rigid-rotor stability. ASLE Transactions, 25,221-228.

27. Nair, K.P.,et al.(1987). A study of elastohydrodynamic effects in a three-lobe journal bearing. Tribology International, 20 , 125-132.

28. Chandrawat, H.N., \& Sinhasan, R. (1990). A study of elastohydrodynamic lubrication in a three-lobe journal bearing. Wear, 137, 1-13.

29. Chandrawat, H.N., \& Sinhasan, R. (1988). A study of two lobe journal bearing considering elastohydrodynamic effects. Wear, 127, 161-177.

30. Chandrawat, H.N., \& Sinhasan, R. (1987). A comparison between two numerical techniques for hydrodynamic journal bearing problems. Wear, 119, 78-87.

31. Chasalevris, A. (2015). Analytical evaluation of the static and dynamic characteristics of three-lobe journal bearings with finite length. Journal of Tribology, 137, 41701-1 -41701-16

32. Malik, M. (1983). The analysis of symmetric and tilted four-lobed journal bearing configurations. ASLE Transactions, 26, 264-269.

33. Pai, B., \& Majumdar, B.C. (1992). Stability of submerged four-lobe oil journal bearings under dynamic load. Wear, 154, 95108.

34. Bhushan, G.,et al.(2002). Stability analysis of four-lobe pressure-dam bearings. Tribology Letters, 13, 1-7.

35. Morgan, V.T., \& Cameron, A. (1957). Mechanism of lubrication in porous metal bearings. Proceedings of Conference on Lubrication \& Wear,151-157

36. Rahmatabadi, A.D.,et al.(2010a). Micropolar lubricant effects on the performance of noncircular lobed bearings. Tribology International, 43,404-413.

37. Rahmatabadi, A.D.,et al.(2010b). Performance analysis of micropolar lubricated journal bearings using GDQ method. Tribology International, 43, 2000-2009.

38. Chetti, B. (2014). Stability analysis of three-lobe journal bearing lubricated with a micropolar fluids. International Journal of Chemical, Molecular, Nuclear, Materials and Metallurgical Engineering, 8, 1464-1469.

39. Mehrjardi, M.Z.,et al.(2016a). A study on the stability performance of non-circular lobed journal bearings with micropolar lubricant. Journal of Engineering Tribology, 230, 14-30.

40. Sharma, S., \& Krishna, C.M. (2015).Effect of L/D ratio on the performance of two-lobe pressure dam bearing micropolar lubricated. International Journal of Pure and Applied Research in Engineering and Technology, 1, 1-7.

41. Rahmatabadi, A.D.,et al.(2011).Preload effects on the static performance of multi-lobe fixed profile journal bearings with micropolar fluids. Journal of Engineering Tribology, 225, 1-13.

42. Mehrjardi, M.Z.,et al.(2016b). A comparative study of the preload effects on the stability performance of noncircular journal bearings using linear and nonlinear dynamic approaches. Journal of Engineering Tribology, 230,797-816.

43. Sinhasan, R. \& Goyal, K.C. (1995).Transient response of a two-lobe journal bearing lubricated with non-Newtonian lubricant. Tribology International, 28,233-239. 
44. Guha, S.K. (2004). A theoretical analysis of dynamic characteristics of finite hydrodynamic journal bearings lubricated with coupled stress fluids. Journal of Engineering Tribology, 218,125-133.

45. Glienicke, J.,et al.(1980).Practical determination and use of bearing dynamic coefficients. Tribology International, 13, 297309.

46. Li, D.F.,et al.(1980).Stability and transient characteristics of four multilobe journal bearing configurations. Journal of Lubrication Technology, 120,291-298.

47. Wahed, N.A.,et al.(1982). Stability and unbalance response of large turbine bearings. Transactions of ASME, 104, 66-75.

48. Chandra, M.,et al.(1983).Comparative study of four gas-lubricated noncircular journal bearing configurations. Tribology International, 16,103-108.

49. Lund, J.W. (1967). A theoretical analysis of whirl instability and pneumatic hammer for a rigid rotor in pressurized gas journal bearings. Journal of Lubrication Technology, 89,154-165.

50. Lund, J.W. (1968b). Calculation of stiffness and damping properties of gas bearings. Journal of Lubrication Technology, 90,793-803.

51. Dargaiah, K.,et al. (1993). Finite element method for computing dynamic coefficients of multilobe bearings. Tribology Transactions, 36, 73-83.

52. Shang, L. \& Dien,I.K. (1989). A matrix method for computing the stiffness and damping coefficients of multi-arc journal bearings. Tribology Transactions, 32,396-404.

53. Rao, T.V.V.L.N.,et al(2001). A methodology for dynamic coefficients and nonlinear response of multi-lobe journal bearings. Tribology Transactions, 44,111-117.

54. Rao, T.V.V.L.N., \& Sawicki, J.T. (2001). Dynamic coefficient prediction in multi-lobe journal bearings using a mass conservation algorithm. Tribology Transactions, 46,414-420.

55. Elrod, H.G. (1981). A cavitation algorithm. Journal of Tribology, 103,350-354. 
